\title{
Effect of planting grasses on vegetation restoration on the bare land
}

\author{
Tiejun SUN ${ }^{1, ~ a}$, Juying WU ${ }^{2, b}$, Wei HU ${ }^{3, c}$, Haiming KAN ${ }^{4, d}$, Zhuo PANG ${ }^{5, e}$
}

Beijing Research \& Development Center of Grass and Environment, Beijing Academy of Agriculture
and Forestry Sciences, Banjing, Haidian District, Beijing 100097, China.

acorresponding author 1: srtj_cau@163.com, ${ }^{\mathrm{b}}$ corresponding author 2: wujuying1@263.net,

chuwei102205@163.com, ${ }^{d}$ kanhaiming@hotmail.com, ${ }^{e}$ pangzh-84@163.com

Keywords: planting grass, vegetation restoration, bare land

Abstract. Experiment was executed to study characteristics of restoring vegetations after Medicago sativa and Bromus inermis planted on the bare land. The results indicated that vegetations restored rapidly after Medicago sativa and Bromus inermis planted on the bare land in Yanqing county, Beijing. And vegetation cover and aboveground biomass were over $90 \%$ and $6275.6 \mathrm{~kg} / \mathrm{hm}^{2}$ in the year which Bromus inermis planted. Next year, vegetation cover and aboveground biomass of Medicago sativa grassland were over $90 \%$ and $7094.2 \mathrm{~kg} / \mathrm{hm}^{2}$. Meanwhile, species reached 9-13, and diversity indices of two grasslands reached 0.032-0.0754 in the year which Bromus inermis and Medicago sativa planted. Then diversity index of Medicago sativa grassland reached 0.6782 next year. Moreover, annual species decreased and perennial species increased in the year which Bromus inermis and Medicago sativa planted. But important value of planted grass decreased and natural grass species increased remarkably next year after Medicago sativa planted, which was beneficial to succession of natural plant community rapidly. However, important value of planted grass increased next year after Bromus inermis planted, which was beneficial to community structure stability of artificial grassland.

\section{Introduction}

It is complicated and variform for bare land to take shape, and it is one of main types of degraded ecosystems. There are many main problems for bare land to solve. For example, there is less effective vegetation cover on the bare since it is a long time for natural vegetation to restore to be good, so that soil is more and more droughty, and soil and water conservation are worse and worse ${ }^{[1,2]}$. Naturally, in the early stage of natural vegetation restoring on the bare land, there are more annual species and fewer perennial species in the plant community, which affects severely the direction and speed of plant community succession ${ }^{[3]}$. Then amount and species of annual grasses decreased gradually with community succession, while amount and species of perennial grasses with zonal indication increased. Thus important value and diversity of species and vegetation cover and biomass come into main indices to vegetation restoration ${ }^{[4,5]}$. In the short period, it is benefit for artificial grassland establishment to shaping more stable community composition and structure, since there are more cover and biomass, better soil physical and chemical property and faster community succession after grass planting ${ }^{[6-8]}$. So vegetation cover, biomass, species diversity and important value were measured continuously after artificial grasslands with anti-drought Medicago sativa and Bromus inermis established on the bare land. Then effect of leguminous and gramineous grasses planting on vegetation restoring was studied so as to find feasible methods to restore vegetation on the bare land.

\section{Experiment materials}

Bromus inermis Leyss and Medicago sativa Linn are all from Canada which is original locality.

\section{Experimental set-up and methods}

Experimental set-up: Experiment area located on the bare land in Zhangshanying Town, Yanqing County, Beijing. Artificial grasslands of Medicago sativa and Bromus inermis established in June, 2014. Vegetation restoration by planting Bromus inermis (VB) and Medicago sativa (VM) were 
experimental treatments, and bare land was $\mathrm{CK}$, which repeated three times. Then effect of different treatments of vegetation restoration on the bare land was studied.

Biomass and cover: Vegetation cover in the sample plot of $1 \mathrm{~m} \times 1 \mathrm{~m}$ was measured though First Growth instrument made in Decagon Company in every September after it was chosen randomly in the restoring vegetation, which repeated there times. Then all of aboveground biomass in the sample plot was cut, which repeated three times, and dry matter weighed after drying enough under $80^{\circ} \mathrm{C}$.

Important value and Simpson's diversity index: Plant species, number and cover were counted after sample plot of $1 \mathrm{~m} \times 1 \mathrm{~m}$ was chosen randomly in the restoring vegetation in every September, which repeated there times. Then Simpson's diversity index was calculated though next formula. $\mathrm{D}=1-\sum(\mathrm{Pi})^{2}$. Pi was a ratio of number of species $\mathrm{i}$ in total species. Then important value was calculated though next formula. $\mathrm{IV}=\mathrm{D}+\mathrm{F}+\mathrm{C}$. $\mathrm{D}$ was relative density. $\mathrm{F}$ was relative frequency. $\mathrm{C}$ was relative cover.

\section{Results and discussion}

Effect of different treatments on biological character of restored vegetation. Biological characters of restored vegetation were measured in September after artificial grasslands of Medicago sativa and Bromus inermis were established on the bare land in June, 2014. Vegetation cover of Medicago sativa and Bromus inermis were 96.6\%-97.5\%, which the difference between them was not significant. Then vegetation cover of Medicago sativa and Bromus inermis were 97.8\%-97.9\% in October, 2015. So there were beneficial for Medicago sativa and Bromus inermis planting to vegetation restoration on the bare land in Yanqing County. Moreover, overground biomass of Medicago sativa was $4991.5 \mathrm{~kg} / \mathrm{hm}^{2}$ in September, 2014, which was less than $6275.6 \mathrm{~kg} / \mathrm{hm}^{2}$ of Bromus inermis grassland. But overground biomasses of Medicago sativa grassland reached to $7094.2 \mathrm{~kg} / \mathrm{hm}^{2}$ rapidly in October, next year, which was more than $5180.3 \mathrm{~kg} / \mathrm{hm}^{2}$ of Bromus inermis grassland significantly. Thus effect of Bromus inermis planting on overground biomass of restoring vegetation on the bare land was better than that of Medicago sativa planting in the year which grassland was established. But it was opposite next year that effect of Medicago sativa planting on overground biomass on the bare land was better (Table 1).

Table 1 Vegetation cover and overground biomass in different grasslands

\begin{tabular}{ccccc}
\hline Measured Time & \multicolumn{2}{c}{ Vegetation cover $(\%)$} & \multicolumn{2}{c}{ Overground biomass $\left(\mathrm{kg} / \mathrm{hm}^{2}\right)$} \\
\cline { 2 - 5 } & VM & VB & VM & VB \\
\hline Sep.2014 & $96.6 \mathrm{a}$ & $97.5 \mathrm{a}$ & $4991.5 \mathrm{~b}$ & $6275.6 \mathrm{a}$ \\
Oct.2015 & $97.8 \mathrm{a}$ & $97.9 \mathrm{a}$ & $7094.2 \mathrm{a}$ & $5180.3 \mathrm{a}$ \\
\hline
\end{tabular}

Note: Numbers with different letters in a column showed different significantly in the 0.05 level.

Effect of different treaments on species diversity. Simpson's diversity index was calculated after the number of species was measured from 2014 to 2015 . The results showed that species diversity index of Medicago sativa grassland was 0.0754 in September, 2014, which was higher than 0.032 of that of Bromus inermis grassland. Species diversity index of Bromus inermis grassland was 0.0329 in October, 2015, which was no more change than before. But species diversity index of Medicago sativa grassland reached to 0.6782 with species increasing rapidly in 2015, which was 20.6 times of that of Bromus inermis grassland. Thus species diversity of vegetation could increase rapidly by planting Medicago sativa and Bromus inermis on the bare land. But effect of Medicago sativa planting on improving species diversity was better than that of Bromus inermis planting (Fig.1). 


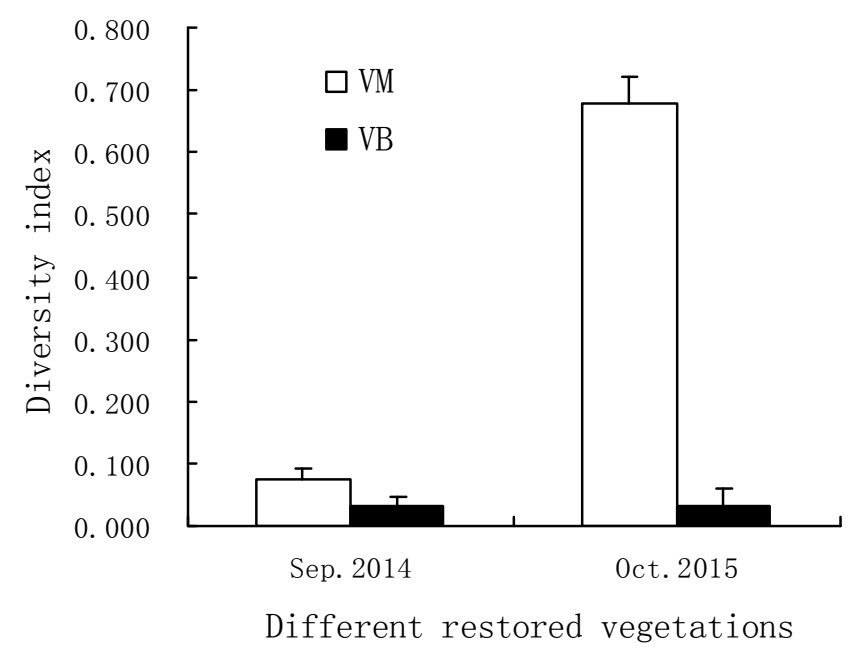

Fig. 1 Species diversity indexes in different grasslands in the Sep. 2014 and Oct. 2015

Effect of Medicago sativa planting on important values of vegetation species (VM). Important value indicates species importance in the community through relative density, relative frequentness and relative cover. Important values of species had been studying for two years after Medicago sativa grassland established in June, 2014. The results showed that there were 9 grasses in the community including 5 annual species and 4 perennial species in September, 2014. The number of species of Medicago sativa grassland reached to 15 in October, 2015. Among them, annual species were 7 which increased fewer, and perennial species improved to 8 greatly which were more than annual species. Thus species on the bare land increased greatly by planting Medicago sativa in Yanqing county. Furthermore, community structure composed mainly by annual species came into that composed mainly by perennial species. Meanwhile, important values of different species changed greatly. Important value of Medicago sativa reached to the greatest of 197.0 in September, 2014, but decreased to 50.0 in October, 2015. However, important values of natural species reached to 1.8-64.4 in 2015 from 3.0-28.6 in 2014. Especially, important value of Carex heterostachya was 0 in the year which Medicago sativa planted, and reached to 64.4 next year which was the greatest in the community. Otherwise, there was a new species next year which Medicago sativa planted, Robinia pseudoacacia, which was a tree, and its important value was 3.5. Thus important value of Medicago sativa reduced obviously, natural species rose gradually, and ratio and importance of perennial species in the community were improved so that natural vegetation on the bare land could restore rapidly due to shorter community succession after two years which Medicago sativa planted (Fig.2).

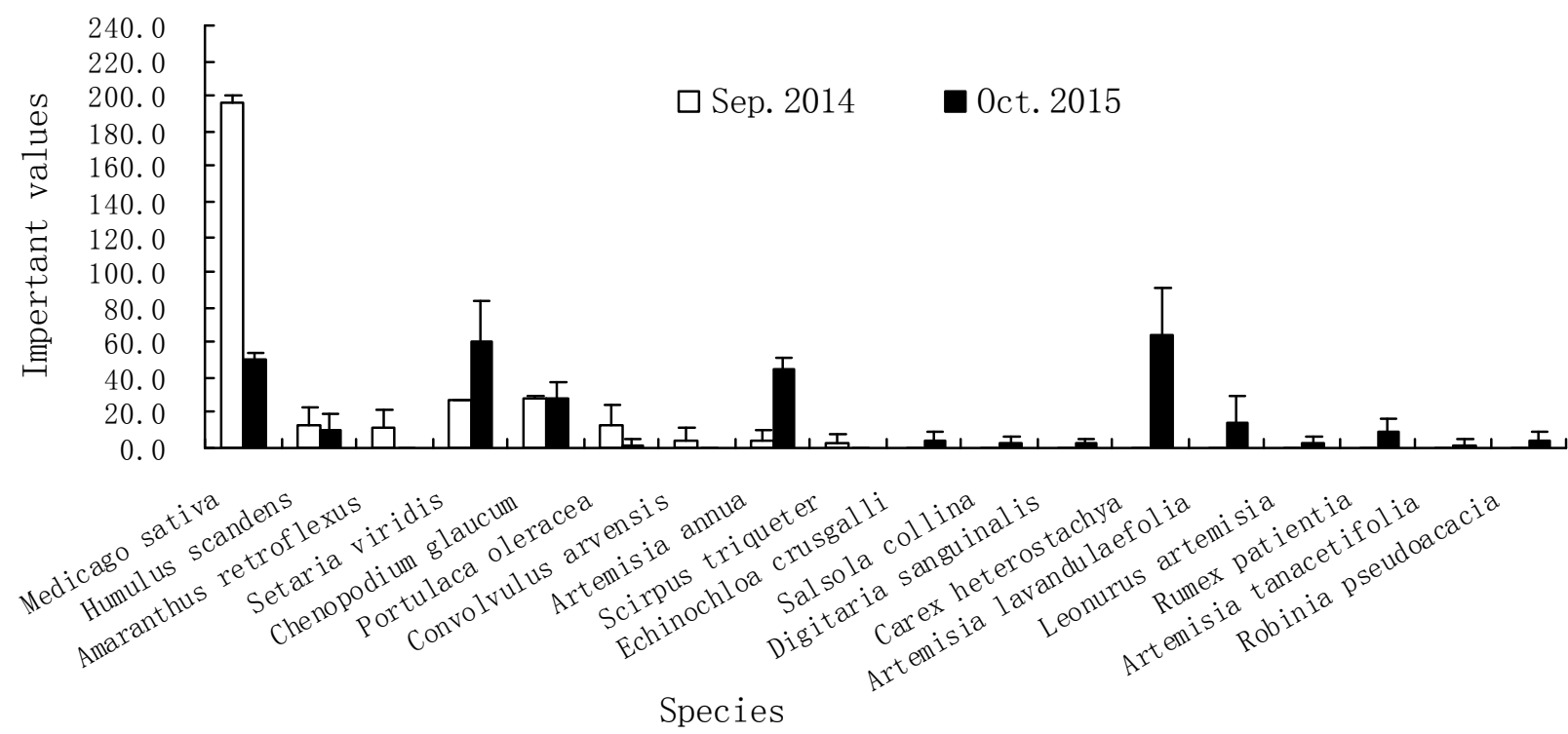

Fig. 2 Species important values in the Medicago sativa grassland in the Sep. 2014 and Oct. 2015 
Effect of Bromus inermis planting on important values of vegetation species (VB). Important values of species in Bromus inermis grassland were studied in September, 2014. The results showed that there were 13 grasses in the community. Among them, there were 8 annual species, which were more than 5 perennial species. Then plant species in Bromus inermis grassland reduced to 10. Annual and perennial species were all 5. Among them, the number of perennial species did not change, but the number of annual plant species reached to 5 after decreasing by 3 . So natural annual grasses increased obviously on the bare land in the year which Bromus inermis planted in Yanqing county, but decreased rapidly next year. And perennial grasses have no change. Otherwise, important values of different plant species changed greatly after Bromus inermis planted. Important values of Bromus inermis was 197.5, the most of all the species, in the year which grassland established, then increased to 227.2 next year. Meanwhile, the limit of important values of natural species reduced to 3.5-16.9 from 1.9-24.7. Among them, important values of annual species decreased obviously. Important values of Portulaca oleracea, Setaria viridis, Chenopodium glaucum, and Digitaria sanguinalis decreased to 0 in 2015 from 10.5-24.7 in 2014. Important values of perennial species of Carex heterostachya, Artemisia tanacetifolia, Artemisia capillaries, Hemerocallis citrine increased to 4.1-13.7 from 0. Thus there was helpful for Bromus inermis planting to keep stability of community structure of artificial grassland in Yanqing county. Because dominance of Bromus inermis was continue to keep after Bromus inermis planted on the bare land. And perennial species appeared gradually while annual species reduced (Fig.3).

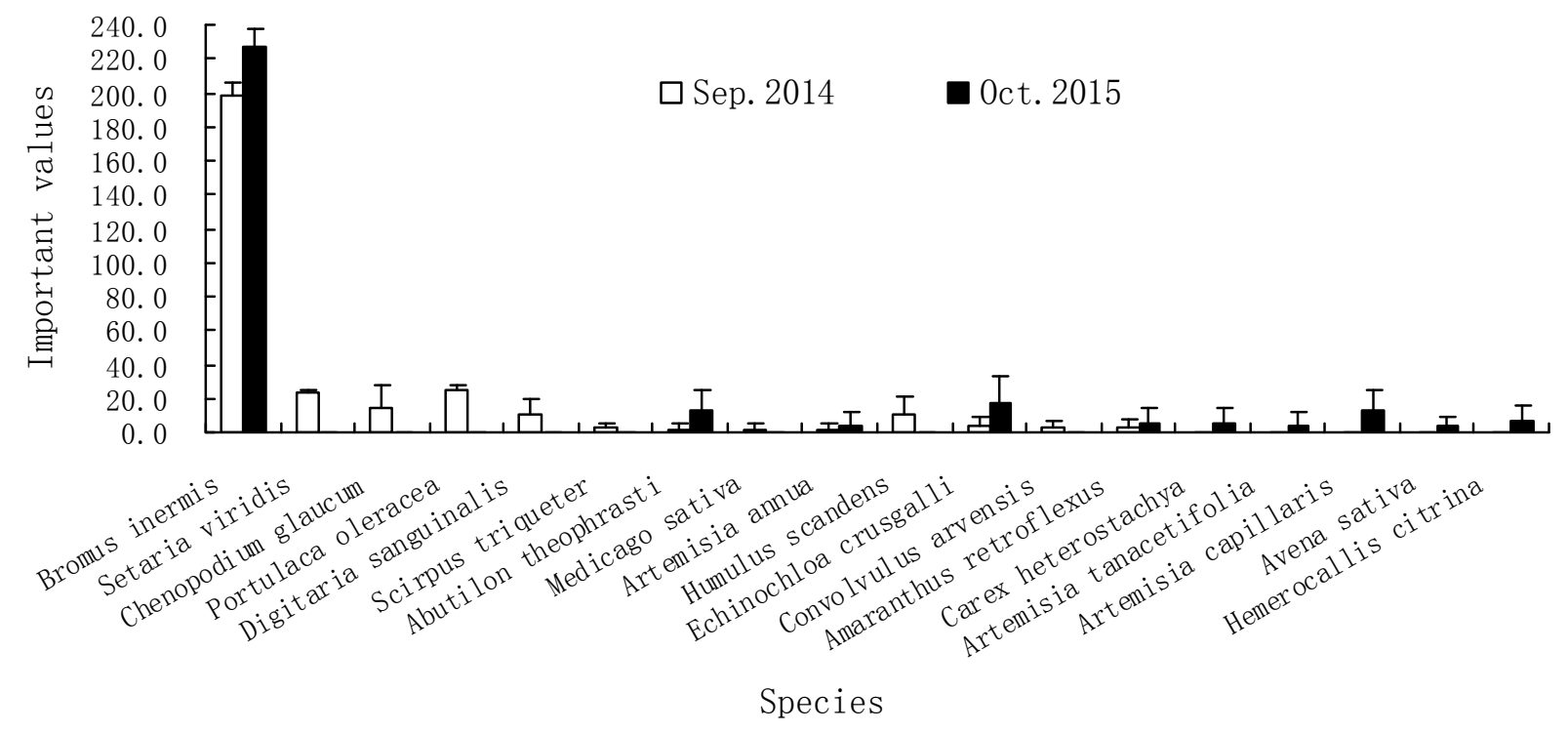

Fig. 3 Species important values in the Bromus inermis grassland in the Sep. 2014 and Oct. 2015

\section{Conclusions}

Vegetation on the bare land in Yanqing county could all restore rapidly by planting Medicago sativa and Bromus inermis. Vegetation covers reached to over 95\% after two grasses planted, and keep good on to next year. However, there were different effects for Medicago sativa and Bromus inermis to aboveground biomass improve on the bare land at different restoration stages. Aboveground biomass of Bromus inermis grassland reached to $6275.6 \mathrm{~kg} / \mathrm{hm}^{2}$ in the year which planted. And aboveground biomass of Medicago sativa grassland reached to $7094.2 \mathrm{~kg} / \mathrm{hm}^{2}$ next year after planting.

Plant species on the bare land could increase greatly by planting Medicago sativa and Bromus inermis. Plant species of Medicago sativa grassland were 9, and plant species of Bromus inermis grassland were 13 in the year which grassland established. Species diversity of vegetation on the bare land improved obviously after Medicago sativa and Bromus inermis planted. And species diversity indices reached to 0.032-0.0754. However, effect of Medicago sativa planting for species diversity to improve was better than that of Bromus inermis planting. Species diversity index of Medicago sativa 
grassland reached to 0.6782 next year after planting, which was 20.6 times of that of Bromus inermis grassland.

Annual species on the bare land decreased by planting Medicago sativa and Bromus inermis, and perennial species increased. Then the community with annual plant species mostly changed into that with perennial plant species mostly. But effect of planting Medicago sativa and Bromus inermis on vegetation restoration on the bare land was different partly. Important value of Medicago sativa reduced obviously to 50.0 from 197.0 after Medicago sativa had planted for two years. Important values of natural plant species extended to 1.8-64.4 in the second year from 3.0-28.6 in the first year which grassland established. So restoration succession of vegetation on the bare land accelerated. However, dominance of Bromus inermis was strengthened after Bromus inermis had planted for two years. Important value of Bromus inermis was 227.2 in the second year from 197.5 in the first year which grassland established. But important values of natural plant species reduced 3.5-16.9 from 1.9-24.7. So it was helpful for Bromus inermis planting to keep community structure of artificial grassland stability with dominance of planting grass.

\section{Acknowledgements}

This work was financially supported by Beijng Finance Bureau Science and Technology Innovation Project of "Beijng Monitoring Station of Degraded Ecosystem Restoring in the Long Term Construction (KJCX20140301)" and "Research and Demonstration of Technologies on Efficient Grassland Construction for the Restoration of Sandy Wasteland (KJCX20151201)". Thanks for Beijing Grassland Ecosystem Research Station, Beijing Academy of Agriculture and Forestry Sciences.

\section{References}

[1] Khater C, Arnaud M, Jacques M: Applied Vegetation Science. Vol. 6(2003) p. 199-204.

[2] Walker L R, Zasada J C, Chapin F S I: The role of life history processes in primary succession on an alaskan floodplain. Ecology: (A Publication of the Ecological Society of America). 67(5) (1986), p. 1243-1253. (http://search.proquest.com/docview/49753001?accountid=30720)

[3] Zhang J, Zhao H, Zhang T, Zhao X, Drake S: Journal of Arid Environments, 62(4) (2005), p. 555-566.

[4] Asefa D T, Oba G, Weladji R B, Colman J E: Land Degradation and Development. Vol.14 (2003), p. 25-38.

[5] Martin L M, Moloney K A, Wilsey B J: Journal of Applied Ecology. 42(2) (2005), p. 327-336.

[6] J Zhang and G B Liu: Journal of natural resources. 25(2) (2010), p. 207-217.

[7] Fu H, Pei S, Changgui W C: Agriculture, Ecosystems and Environment. Vol. 124(2008), p. 33-39.

[8] Kirmer A and Mahn E G: Applied Vegetation Science (official organ of the International Association for Vegetation Science4.1) (June 2001). Vol. 4(2001), p. 19-27. 